\title{
Survei Pembelajaran Pendidikan Jasmani, Olahraga dan Kesehatan (PJOK) Materi Bola Voli Mini di Sekolah Dasar
}

\section{Survey of Learning Physical Education, Sports and Health (PJOK) Material Mini Volleyball in Elementary Schools}

\author{
Sujarwo ${ }^{1}$, Windi Widayat ${ }^{2}$ \\ 1,2 Fakultas IImu Keolahragaan, Universitas Negeri Yogyakarta, Indonesia \\ email: jarwo@uny.ac.id ${ }^{1}$ \\ doi : https://doi.org/10.20884/1.paju.2020.2.1.2604
}

\begin{abstract}
Abstrak
Penelitian ini bertujuan untuk mengetahui pelaksanaan pembelajaran bola voli mini di Sekolah Dasar dan metode pembelajaran yang digunakan. Pembelajaran pendidikan jasmani materi bola voli masih bervariasi, sehingga perlu penyesuaian terhadap kondisi anak dan filosofi permainan bola voli agar tujuan pembelajaran tercapai. Metode yang sesuai dengan pendekatan penelitian deskriptif yaitu dengan menggunakan metode survei lapangan.Penelitian ini menggunakan instrumen yang berupa angket yang diisi oleh guru pendidikan jasmani, dan tervalidasi dengan validitas content oleh tiga orang expert dalam bidang pendidikan jasmani. Subjek Penelitian berjumlah 30 orang guru pendidikan jasmani yang termasuk dalam kelompok kerja guru (KKG) di Kecamatan Sewon, Bantul. Teknik analisis data menggunakan teknik persentase berdasarkan jumlah guru yang melakukan metode pembelajaran yang dilakukan dibagi dengan jumlah guru total kemudian dikalikan $100 \%$. Hasil penelitian menunjukkan bahwa: sejumlah 16 orang guru atau 53.3\% menggunakan pendekatan teknik dalam pembelajaran bola voli mini, 9 orang guru atau $30 \%$ yang menggunakan pendekatan bermain, dan 5 orang guru menggunakan pendekatan TGFU dalam pembelajaran pendidikan jasmani materi bola voli mini di sekolah dasar. Model pembelajaran dengan pendekatan bermain, teknik/drill, maupun taktik (TGFU) memiliki kelebihan dan kekurangan masing-masing dan sangat bergantung dengan kondisi anak, kondisi penunjang pembelajaran pendidikan jasmani yang dimiliki sekolah, juga kondisi pengetahuan termasuk pemahaman guru tentang filosofi dalam materi pembelajaran yang akan disampaikan. Kombinasi antara ketiganya sangat baik dengan modifikasi penyampaian yang menarik.
\end{abstract}

Kata Kunci : Survei, Pembelajaran, Bola Voli Mini

\begin{abstract}
This study aims to determine the implementation of mini volleyball learning in elementary schools and the learning methods used. Physical education learning volleyball material is still varied, so it needs to be adjusted to the condition of children and the philosophy of volleyball games so that learning objectives are achieved. The method that suits the descriptive research approach is to use the field survey method. This study uses an instrument in the form of a questionnaire
\end{abstract}


filled out by physical education teachers, and validated with content validity by three experts in the field of physical education. Research subjects totaled 30 physical education teachers included in the teacher working group (KKG) in the District of Sewon, Bantul. The data analysis technique used percentage technique based on the number of teachers who did the learning method divided by the total number of teachers then multiplied by $100 \%$. The results showed that: a total of 16 teachers or 53.3\% used a technical approach in learning mini volleyball, 9 teachers or $30 \%$ used a play approach, and 5 teachers used the TGFU approach in learning physical education of mini volleyball material in elementary schools . Learning model with play approach, technique / drill, and tactics (TGFU) has advantages and disadvantages of each and is very dependent on the condition of the child, the supporting conditions for physical education learning owned by the school, also the condition of knowledge including the teacher's understanding of philosophy in the learning material that is will be delivered. The combination of the three is very good with interesting delivery modifications.

Keywords: Survey, Learning, Mini Volleyball

\section{PENDAHULUAN}

Penelitian ini bertujuan untuk mengetahui pelaksanaan pembelajaran bola voli mini yang berlangsung di Sekolah Dasar dan metode pembelajaran yang digunakan oleh guru pendidikan jasmaninya. Masih bervariasinya metode dan model pembelajaran yang digunakan oleh guru pendidikan jasmani tentang materi bola voli perlu disesuaikan dengan kondisi anak dan filosofi yang ada dalam bola voli agar tujuan pembelajaran dapat tercapai. Realita yang ada di sekolah dasar,menunjukkan bahwa saat ini masih terdapat guru pendidikan jasmani olahraga dan kesehatan yang belum memiliki kesamaan persepsi dan skill dalam menyampaikan pembelajaran pendidikan jasmani olahraga dan kesehatan di sekolahnya.

Beberapa hal yang menyebabkan terjadinya kondisi tersebut di antaranya: sarana prasarana yang dimiliki, kemampuan guru dalam menyampaikan materi baik pendekatan mengajarnya maupun penguasaan guru terhadap materi, inovasi dan kreatifitas guru dalam menyampaikan materi, kedalaman konsep dan aplikasi yang dimiliki guru, karakteristik anak modern, model pembelajaran pendidikan jasmani yang kurang jelas aplikasinya, dan keterbatasan referensi tentang pendidikan jasmani sebagai bahan pembelajaran. Banyaknya pendekatan pembelajaran yang kurang jelas dalam materi, tujuan dan manfaatnya dapat membingungkan guru pendidikan jasmani di sekolah untuk menyampaikan materi bola voli. Hendaknya ada pelatihan khusus bagi guru sebelum 
Sujarwo, Windi Widayat | Survei Pembelajaran Pendidikan Jasmani, Olahraga dan Kesehatan (PJOK) Materi Bola Voli Mini di Sekolah Dasar

menyampaikan materi yang ada di kurikulum secara komprehensif dan utuh, sehingga akan memudahkan pelaksanaan pembelajaran di sekolah.

Model pembelajaran yang baik hendaknya model tersebut mudah digunakan oleh guru dan secara lengkap dimulai dari petunjuk model dan juga metode, materi dan sampai tahap evaluasi model pembelajaran sehingga guru akan terbantu dengan adanya model tersebut (Festiawan, Ngadiman, Kusuma, Nurcahyo, \& Kusnandar, 2019; Wicaksono, Kusuma, Festiawan, \& Widanita, 2020).oleh karena itu mutlak model pembelajaran yang akan diberikan harus memiliki ciri di atas. Realita saat ini guru masih menyampaikan materi pembelajaran sesuai dengan keinginan mereka masing-masing dan kemampuan kebanyakan guru masing-masing terlebih kesukaan olahraga yang disenangi guru tersebut mesti medapatkan porsi yang lebih, hal tersebut bisa menjadi kekurangan dan juga kelebihan yang guru pendidikan jasmani di Sekolah Dasar.

Berikut beberapa model pembelajaran yang dipakai guru pendidikan jasmani di sekolah dasar, di antaranya: 1) Model pembelajaran dengan pendekatan Bermain; 2) Model pembelajaran pendidikan jasmani pendekatan Taktik (TGFU); dan 3) Model pembelajaran Teknik atau Drill. Berikut kelebihan dan kekurangan dari tiga model pembelajaran di atas:

\section{Model Pembelajaran Pendekatan Bermain (Sport Education)}

Metode pendekatan bermain merupakan salah satu metode mengajar PJOK di sekolah yaitu dengan peserta didik membentuk kelompok belajar atau tim danbertanding antar sesama tim. Metode pembelajaran dengan pendekatan bermain lebih memfokuskan pada how to win, sehingga dapat membentuk seorang individu yang ingin jadi pemenang dalam kehidupannya (Piper, 2014). Dalam pendidikan jasmani dengan pendekatan bermain memiliki kelebihan bahwa setiap orang dapat ikut berpartisipasi dalam pembelajaran, tidak bias gender, semua orang terlibat dalam permainan (Foster \& Roberts, 2019).

Hasil penelitian menunjukkan bahwa sebanyak $76 \%$ anak usia 5-10 tahun lebih menyukai pembelajaran dengan permainan yang berbentuk kompetisi (Quick et al., 2013). Siswa (anak) akan memperoleh keterampilan yang sangat penting dari pembelajaran dengan metode bermain, diantaranya: kepemimpinan, disiplin diri, dan ketahanan diri (Information Policy Team, 2019). Pendekatan bermain juga mengajarkan kepada anak untuk memiliki sifat toleransi (Dacica, 2014). Pembelajaran dengan pendekatan bermain 
sangat elegan apabila digunakan dalam materi permainan tradisional (Aggerholm, Standal, \& Hordvik, 2018). Kata what, how and why dalam pendekatan bermain ini perlu diadaptasikan kepada anak dalam setiap pembelajaran (Hordvik, MacPhail, \& Ronglan, 2017). Berikut kelebihan dan kekurangan metode ini:

Tabel 1. Model pembelajaran bermain (Sport Education)

\begin{tabular}{|c|c|}
\hline Kelebihan & Kekurangan \\
\hline $\begin{array}{l}\text { Anak terbiasa belajar dan bekerja dalam tim; } \\
\text { Memiliki rasa dan motivasi tinggi; Student centered, } \\
\text { aktualisasi diri, percaya diri, kerja sama, motivasi } \\
\text { tinggi }\end{array}$ & $\begin{array}{l}\text { Skill kurang bisa dibentuk karena belajar sendiri; } \\
\text { Terlalu fokus dengan pertandingan sehingga materi } \\
\text { kadang tidak tersampaikan, losser }\end{array}$ \\
\hline
\end{tabular}

\section{Model Pembelajaran Pendekatan Taktik (TGFU)}

Metode pembelajaran taktik merupakan salah satu metode mengajar PJOK juga, namun lebih fokus ke taktik dalam suatu permainan(Festiawan, 2020). Teaching Games for Understanding (TGFU) merupakan model pembelajaran yang menekankan taktik pemainan untuk dapat dimengerti sebagai pengenalan pertama, siswa harus mengetahui kenapa dan kapan keterampilan itu diperlukan dalam konteks permainan (Qohhar \& Pazriansyah, 2019). Adanya simulasi yang dilakukan oleh anak akan mampu mengembangkan kemampuan problem solving dalam melakukan gerak, melakukan hipotesis, memanipulasi variabel, mengumpulkan dan generalisasi data dan menganalisis gerak, menghubungkan dan menggambarkan bahkan menyimpulkan gerak (Sherman \& Kurshan, 2004).

Pembelajaran pendidikan jasmani dengan model TGFU akan membuat anak memiliki kompetensi, kemandirian dan kebiasaan untuk hidup aktif (Gil-Arias, Harvey, Carceles, Praxedes, \& Del Villar, 2017). Praktek pembelajaran TGFU dikelompokkan dalam empat katagori permainan, di antaranya: invasi, net/wall, striking/fielding, dan target (Webb, Pearson, \& Forrest, 2006). Model pembelajaran dengan metode TGFU ini sangat sesuai untuk guru pendidikan jasmani yang akan menyampaikan materi permainan dan olahraga (Stolz \& Pill, 2013). Berikut kelebihan dan kekurangan metode ini:

Tabel 2. Model pembelajaran TGFU

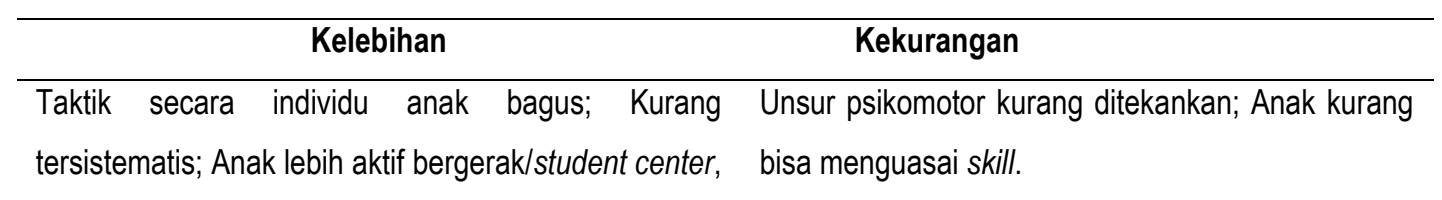


mengembangkan ide, hipotesis, problem solving,

kemandirian.

\section{Model pembelajaran pendekatan Teknik atau Drill}

Pembelajaran dengan pendekatan teknik ini merupakan suatu pendekatan pembelajaran atau metode pembelajaran PJOK dengan cara melakukan drilling dalam aktivitas yang dilakukan siswa. Pada pembelajaran pedekatan teknik berfokus pada guru (Aktop \& Karahan, 2012). Guru pendidikan jasmani dengan pendekatan teknik ini harus menguasai keterampilan yang akan diajarkan (Gumbo, Magonde, \& Nhamo, 2017). Guru dengan pendekatan teknik juga harus mengutamakan pengetahuan atau kognitif anak terhadap gerak yang akan dilakukanya (Raiola \& Tafuri, 2015).

Bantuan teknologi bagi sekolah yang memiliki kemampuan dalam menyediakan alat fasilitas sangat menunjang pembelajaran dengan pendekatan teknik, sehingga meminimalisir guru dalam memberikan contoh gerak yang salah, bisa dicarikan melalui teknologi analisis gerak yang benar (Eberline \& Richards, 2013). Guru harus dibekali dengan pelatihan aplikasi gerak dengan teknologi agar dapat menyampaiakan materi pendidikan jasmani dengan benar (Baek, Keath, \& Elliot, 2018). Kelebihan dan kekurangan dari pendekatan teknik ini adalah:

Tabel 3. Model pembelajaran teknik/drill

\begin{tabular}{lll}
\hline \multicolumn{2}{c}{ Kelebihan } & \multicolumn{1}{c}{ Kekurangan } \\
\hline Hasil akhirnya anak memiliki psikomotor yang & Unsur lain seperti kognitif dan afektif kurang ditekankan; \\
dominan; $\quad$ Sistematis & pembelajarannya; & Peserta didik banyak mengantri/kurang kesempatan \\
Teacher centered & & bergerak; Kreatifitas kurang \\
\hline
\end{tabular}

\section{METODE}

Metode penelitian yang digunakanadalah deskriptif kuantitatif dengan survei. Instrumen penelitian menggunakan angket yang diisi oleh guru pendidikan jasmani yang sudah tervalidasi dengan validitas content, yaitu dengan menggunakan tiga expert dibidang pendidikan jasmani. Subjek penelitian berjumlah 30 orang guru pendidikan jasmani yang termasuk dalam kelompok kerja guru (KKG) di Kecamatan Sewon, Bantul. Teknik analisis data menggunakan teknik persentase berdasarkan jumlah frekuensi guru 
yang melakukan metode pembelajaran yang dilakukan dibagi dengan jumlah keseluruhan gurukemudian dikalikan 100\%. Rumus yang digunakan: $P=\frac{\mathrm{f}}{\mathrm{N}} \times 100 \%$.

HASIL

Berdasarkan hasil pengumpulan data dilapangan tentang model pembelajaran yang telah diaplikasikan guru untuk menyampaikan materi permainan bola voli mini, diperoleh hasil sebagai berikut:

Tabel 4. Model pembelajaranPenjas di Kecamatan Sewon Bantul

\begin{tabular}{ccc}
\hline Metode Pembelajaran & Jumlah Guru PJOK & Persentase (\%) \\
\hline Bermain & 9 & 30 \\
\hline TGFU & 5 & 16.7 \\
\hline Teknik/drill & 16 & 53.3
\end{tabular}

Berdasarkan data yang diperoleh,menunjukkan bahwa sejumlah 16 orang guru atau 53.3\% menggunakan pendekatan teknik dalam pembelajaran bola voli mini, 9 orang guru atau $30 \%$ yang menggunakan pendekatan bermain, dan 5 orang guru menggunakan pendekatan TGFU dalam pembelajaran pendidikan jasmani materi bola voli mini pada siswa Sekolah Dasar.

\section{Model pembelajaran penjas materi voli mini}

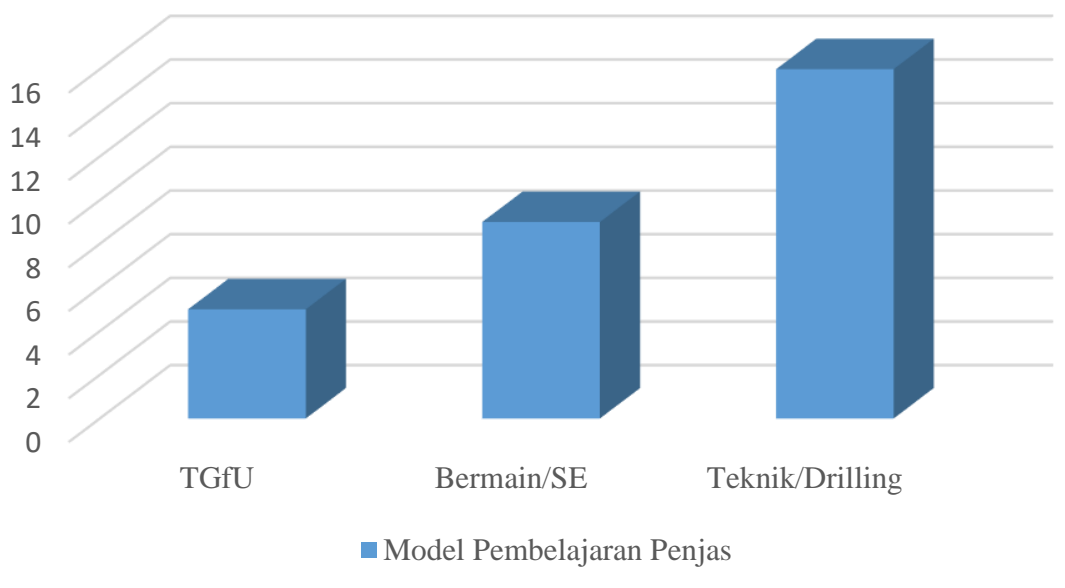

Gambar 1. Grafik Model pembelajaran Penjas materi bola voli mini 
Sujarwo, Windi Widayat | Survei Pembelajaran Pendidikan Jasmani, Olahraga dan Kesehatan (PJOK) Materi Bola Voli Mini di Sekolah Dasar

\section{PEMBAHASAN}

Hasil penelitian menunjukkan bahwa guru pendidikan jasmani di sekolah dasar masih banyak menggunakan pendekatan teknik dalam menyampaikan materi permainan bola voli mini. Hal ini dikarenakan guru merupakan role model bagi anak, dan guru masih memiliki percaya diri terhadap kemampuan memberikan contoh materi gerak ke anak yang menurut guru masih benar. Guru pendidikan jasmani merupakan salah satu faktor penting pada saat mengajar pada siswa level bawah, dalam mengembangkan potensi kemampuan dan keterampilan menuju profesional (Ningthoujam, Nongthombam, \& Sunderchand, 2017). Pada kelompok guru dengan metode pendekatan bermain, sangat mengedepankan unsur permainan bola voli yang didalamnya berisi bermain antara dua tim yang bertanding. Untuk lebih kuatnya manfaat pembelajaran dengan metode bermain atau kompetisi hendaknya yang ditekankan adalah peran masing-masing anak dalam tim, bukan hanya hasil akhir (Layn, 2014).

Pembelajaran bermain juga meningkatkan motivasi anak dalam berpartisipasi, (Wallhead \& Ntoumanis, 2004, Budi et al., 2019). Pembelajaran pendekatan bermain akan menghidupkan dan mengembangkan kembali budaya olahraga di masyarakat (Wallhead \& O'sullivan, 2005). Guru yang menerapkan pendekatan metode TGFU masih sedikit karena sangat dipengaruhi oleh budaya suatu daerah. Peran penting pembelajaran dengan pendekatan pemahaman adalah inti dari sebuah gagasan atau ide, namun guru harus mampu mengimplemtasikan dalam materi dan situasi kondisi agar tujuan pendidikan tercapai (Mctighe \& Seif, 2019). Pembelajaran dengan metode pemahaman lebih efektif dari segi penentuan tujuan dan juga evaluasi pembelajaran (Kivunja, 2015). Berdasarkan penjelasan tersebut maka pelaksanaan pembelajaran bagi siswa sekolah dasar lebih diutamakan untuk didesai dalam penguatan pemahaman dalam keterampilan gerak.

Penelitian tentang survei pembelajaran pendidikan jasmani olahraga dan kesehatan materi permainan bola voli ini memiliki fokus penelitian terhadap model pembelajaran yang disampaikan oleh guru pendidikan jasmani di Sekolah Dasar, spesifik pada materi pembelajaran bola voli. Sedangkan penelitian yang lain berfokus pada keseluruhan pembelajaran pendidikan jasmani di Sekolah Dasar.

Keterampilan gerak dasar sangat diperlukan bagi siswa Sekolah Dasar karena pada usia tersebut, anak memiliki perkembangan yang baik dari segi motorik. 
Keterampilan gerak dasar penting dikembangkan pada usia sekolah dasar sebagai dasar perkembangan tahap selanjutnya (Budi, Kusuma, Syafei, \& Stephani, 2019). Pembelajaran bola voli mini dengan pendekatan bermain mampu menfasilitasi kebutuhan siswa sekolah dasar dalam mengembangkan keterampilan gerak dalam olahraga, sehingga perlu dikembangkan dan dierapkan pada pembelajaran permaina di tingkat Sekolah Dasar.

\section{SIMPULAN}

Berdasarkan hasil penelitian dan pembahasan bahwa Model pembelajaran dengan pendekatan bermain, taktik (TGFU), maupun eknik/drill memiliki kelebihan dan kekurangan masing-masing, yang sangat bergantung oleh kondisi anak, kondisi pendukung pembelajaran pendidikan jasmani khususnya materi bola voli yang dimiliki di sekolah, dan kondisi pengetahuan guru tentang filosofi dalam materi pembelajaran yang akan disampaikan. Kombinasi antara ketiganya sangat baik dengan modifikasi penyampaian yang menarik.

\section{REFERENSI}

Aggerholm, K., Standal, O. ., \& Hordvik, M. M. (2018). Competition in Physical Education: Avoid, Ask, Adapt, or Accept? Quest-illinois-NASPE in Higher Education. https://doi.org/https://doi.org/10.1080/00336297.2017.1415151.

Aktop, A., \& Karahan, N. (2012). Physical Education Teacher's View of Effective Teaching Methods in Physical Education. Procedia-Social an Behavioral Sciences. https://doi.org/https://doi.org/10.1016/j.sbspro.2012.05.401s.

Baek, J. ., Keath, A., \& Elliot, E. (2018). Physical Education Teachers' Technology Practices and Challanges. International Journal of Human Movement Science, 12(2). https://doi.org/https://doi.org/10.23949/ijhms.2018.08.12.2.2.

Budi, D. R., Hidayat, R., \& Febriani, A. R. (2019). The Application of Tactical Approaches in Learning Handballs. JUARA: Jurnal Olahraga. https://doi.org/10.33222/juara.v4i2.534

Budi, D. R., Kusuma, M. N. H., Syafei, M., \& Stephani, M. R. (2019). The Analysis of Fundamental Movement Skill in Primary School Student in Mountain Range. https://doi.org/10.2991/icsshpe-18.2019.56

Dacica, L. (2014). The Formative Role of Physical Education and Sports. The 6th International Conference Edu World 2014 "Education Facing Contemporary World 
Sujarwo, Windi Widayat | Survei Pembelajaran Pendidikan Jasmani, Olahraga dan Kesehatan (PJOK) Materi Bola Voli Mini di Sekolah Dasar

Issues". Procedia-Social and Behavioral Sciences. https://doi.org/https://doi.org/10.1016/j.sbspro.2015.02.256.

Eberline, A. D., \& Richards, K. A. R. (2013). Teaching with Technology in Physical Education. Strategies: A Journal for Physical and Sports Educators. https://doi.org/https://doi.org/10.1080/089224562.2013.839522.

Festiawan, R. (2020). Pendekatan Teknik dan Taktik: Pengaruhnya Terhadap Keterampilan Bermain Futsal. Gelanggang Olahraga: Jurnal Pendidikan Jasmani Dan Olahraga, 3(2), 143-155. https://doi.org/https://doi.org/10.31539/jpjo.v3i2.1080

Festiawan, R., Ngadiman, N., Kusuma, I. J., Nurcahyo, P. J., \& Kusnandar, K. (2019). Pengembangan Model Pembelajaran Pendidikan Jasmani Berbasis Games, Education, and Visualisation (GEV) Untuk Meningkatkan Pengetahuan Kesehatan $\begin{array}{llll}\text { Reproduksi Remaja. Jendela Olahraga, } & 4(2), & 13 .\end{array}$ https://doi.org/10.26877/jo.v4i2.3678

Foster, D., \& Roberts, N. (2019). Physical Education, Physical Activity and Sport in Schools. Briefing Paper. House of Commons Library No. 6836.

Gil-Arias, A., Harvey, S., Carceles, A., Praxedes, A., \& Del Villar, F. (2017). Impact of a Hybrid TGFU-Sport Education Unit on Student Motivation in Physical Education. PLOS ONE. https://doi.org/https://doi.org/10.1371/journal.pone.0179876.

Gumbo, S., Magonde, S., \& Nhamo, E. (2017). Teaching Strategies Employed by Physical Education Teachers in Gokwe North Primary Schools. International Journal of Sports, Exercise and Health Reasearch.

Hordvik, M. M., MacPhail, A., \& Ronglan, L. T. (2017). Teaching and Learning Sport Education: a Self-study Exploring the Experiences of a Teacher Educator and Preservice Teachers. Journal of Teaching in Physical Education. Human Kinetics Publisher.

Kivunja, C. (2015). Teaching For Understanding: Spootlighting the Blythe and Associates Pedagogical Model. Cultural and Pedagogical Inquiry.

Layn, T. (2014). Competition within Physical Education: using Sport Education and Other Recomendations to Create Productive, Competitive Environment. UK: Routledge.

Mctighe, J., \& Seif, E. (2019). Teaching For Understanding: a Meaningful Education for 21st Century Learners.

Ningthoujam, R., Nongthombam, B., \& Sunderchand, M. (2017). Innovative Teaching Methods in Physical Education for better Learning. Review Article. International Journal of Curriculum and Resaerch Review (IJCRR). ISSN: 2231-2196.

Piper, S. (2014). The Place and Limits of Competition in the Physical Education Curriculum. Thesis. UK: University of Gloucestershire.

Qohhar, W., \& Pazriansyah, D. (2019). Pengaruh Model Pembelajaran Kooperatif Tipe 
Teaching Games For Understanding (TGFU) Terhadap Peningkatan Hasil Belajar Teknik Dasar Sepakbola. Physical Activity Journal, 1(1), 27-35. https://doi.org/doi:10.32424/1.paju.2019.1.1.1998

Quick, et al. (2013). Evidence on Physical Education and Sport in School. Summary Reports. UK: Department for Education.

Raiola, G., \& Tafuri, D. (2015). Teaching Method of Physical Education and Sports by Prescriptive or Heuristic Learning. Proceeding 9th INSHS International Christmas Sport Scientific Conference. Hungary.

Sherman, T., \& Kurshan, B. (2004). Teaching For Understanding. International Society for Tecnology in Education. Learning \& Leading with Technology, 32(4).

Stolz, S., \& Pill, S. (2013). Teaching Games and Sport for Understanding: Exploring and Reconsidering its Relevance in Physical Education. European Physical Education Review (EPER), 20(1). https://doi.org/https://doi.org/10.1177/1365336X13496001.

Wallhead, T., \& O'sullivan, M. (2005). Sport Education: physical education for the new millennium? Physical Education \& Sport Pedagogy. https://doi.org/10.1080/17408980500105098

Webb, P. I., Pearson, P. J., \& Forrest, G. (2006). Teaching Games For Understanding (TGFU) in Primary and Secondary Physical Education. International Conference for Health, Physical Education, Recreation, Sport and Dance. ICHPER-SD 2006. New Zealand.

Wicaksono, P. N., Kusuma, I. J., Festiawan, R., \& Widanita, N. (2020). Evaluasi penerapan pendekatan saintifik pada pembelajaran pendidikan jasmani materi teknik dasar passing sepak bola. Jurnal Pendidikan Jasmani Indonesia, 16(1), 41-54. https://doi.org/https://doi.org/10.21831/jpji.v16i1.29774 